\title{
Congenital malformations: an inquiry into classification and nomenclature
}

\author{
Harold Kalter
}

\begin{abstract}
In the beginning, as a familiar book recalls, the earth was a formless void. And by separating light from dark, water from sky, life from dust, order came forth. Thus appeared organisation and categorisation. This is to say, classification, since to classify is to make for order and clarity. These are the qualities needed today for the study of congenital malformations and eventual control of their occurrence. What follows is an inquiry into the present state of this desideratum.

(F Med Genet 1998;35:661-665)
\end{abstract}

Keywords: congenital malformations; classification; nomenclature

\section{Classification}

In biology and medicine classification is precisely ordered, in effect is itself a science, with various names. In the former it is called taxonomy and comprises "rules for grouping organisms into categories based on shared characteristics or traits", and in the latter, nosology, the classification of diseases, a "system of categories to which morbid entities are assigned according to some established criteria". ${ }^{1-3}$ In teratology, matters are not that simple. Forty years ago it was written ${ }^{4}$ that "no entirely satisfactory classification of congenital abnormalities has yet been devised", and many would say that is still true today.

Teratology being a branch of medicine, schemes for applying classification to it, like those for all diseases, fall mostly into the categories of aetiology, pathogenesis, and manifestation. Systems of classification founded on aetiology of congenital malformations, in distinction to those based on pathogenesis and outcome, which are directed as much towards theoretical considerations, are expressly oriented to the ultimate prevention of these phenomena.

Knowledge of the causes of congenital malformations, however, is sparse. ${ }^{5}$ And while applauding the breakthrough discoveries in our century that have permitted the major environmental teratogens, ionising radiation, the rubella virus, aminopterin, and thalidomide, to be avoided or rendered harmless, we know that much still remains to be learned, especially about endogenous causes of maldevelopment and their prevention.
CLASSIFICATION BY CAUSE

But this very incomplete accomplishment did not impede the efforts at formulating aetiological classification, which began years ago. An early sweeping view of the causes of abnormal fetal development ${ }^{6}$ put them into the classic partitions of genetic and non-genetic, analogous to Galton's nature and nurture. The former, covering all contingencies, were divided into spontaneous, induced, and somatic mutations, and, bewilderingly, overripeness of the egg. The latter, explicitly defined as "agents affecting the phenotype without effect on the genotype", included all imaginable types of environmental agents, mechanical, actinic, chemical (excess and deficient), temperature (too much, too little), and infective, almost all known through experiments with embryos of rodents, birds, amphibians, and other laboratory creatures, a list hardly enlarged upon even today.

An addition to this overall scheme ${ }^{7}$ contained an important, and still conjectural, consideration: "interactions between mother and fetus of both hereditary and environmental origin", such as antigenic incompatibility and biomaternal factors. Among the standard "influences in the maternal environment", of toxic, nutritional, etc were included psychological traumata, but not with any great confidence in their reality. With the addition to the genetic category of abnormalities associated with chromosomal aberrations, discovered subsequent to the above formulations, these outlines remained essentially unadvanced when a comprehensive summary of the subject appeared some years ago, ${ }^{5}$ and it seems to have continued so until today.

Attempts to classify malformations by causation are hampered by the fact as now known that the appearance of the majority of isolated malformations often gives little clue to their aetiology. The relatively limited final forms that may be attained by individual malformations with few exceptions obscure their possibly diverse causation. By default, therefore, the only unambiguous classificatory scheme existing at present is by abnormality type.

\section{CLASSIFICATION BY TYPE}

A system of putting arrays of malformations into an order based on morphological appearance has some advantages and purposes, for 
example, storage and retrieval of diagnostic data and coding of entries on fetal death and birth records, but by far its predominant use has been in facilitating recognition and comparison. This is the practical and universal basis of classification that necessity has forced on students of human congenital malformations. The entities, however, that can be included in such schemes are numerous, and discussions about what, according to varying needs, they should contain have been arduous. $^{89}$

Among the most comprehensive of descriptive classifications of congenital abnormalities, which it owes of course to the fact that it primarily serves the requirement of indexing hospital and other records for data storage and retrieval, is that contained in the ICD, the International Classification of Diseases. ${ }^{10}$ Aside from the new name given to the chapter in a recent revision devoted to congenital abnormalities, "congenital malformations, deformations and chromosomal abnormalities," and the expansion of some subentries, there is little fundamentally different from previous revisions. It is arranged by system, part, and organ, and includes virtually every deviation from normal, originating prenatally, present at birth, or attributable to conditions present at birth, regardless of medical importance or aetiological status. An early version of the ICD scheme was applied to a birth certificate survey of congenital anomalies in live births in the US by the National Center for Health Statistics. ${ }^{11}$ Some of its features that were criticised were that various items were scattered throughout the ICD under different headings and consequently had to be omitted, and that the system did not accommodate multiple occurrences of malformations.

It is these deficiencies, but particularly the undiscriminating equal weight it gives entities of very different prognosis, giving no guidance to the recording of meaningful abnormalities, that diminish its usefulness to the clinician, public health worker, and epidemiologist, and moreover relinquish an important pedagogic function.

Other extensive formulations have attempted, more or less clumsily, to deal with another of the ICD's shortcomings, that is, the categorisational and coding difficulties presented by the fact that malformations often occur in multiples involving several bodily systems. ${ }^{42}{ }^{13} \mathrm{~A}$ frequent solution to this problem has been to list the combined malformations by what is taken to be the most serious of them, but this ignores the situation in which appreciation of the entire combination is integral to its recognition as a specific constellation of abnormalities, that is, a syndrome. Apropos here is the statement, however ambiguous, that malformation entities may be undetectable unless classified. ${ }^{12}$

The role and importance of classification of congenital malformations are particularly obvious in epidemiological studies of them. Categorisation by type is integral to such studies, since their goal, the discovery of causative factors, can only be approached when the phenomena being investigated are meaningfully denoted. Making this requirement very clear are recent teratoepidemiological studies of limb malformation complexes. Several schematisations for classifying limb defects have been proposed, beginning decades ago, few of which if any give insight into their heterogeneous aetiology and pathogenesis.

Neither the general divisions into which limb defects are often put, reduction, fusion, duplication, or even tranverse, preaxial, postaxial, etc, nor at the other extreme a detailed enumeration, is satisfactory for in depth aetiological investigation. Any hope of unearthing causative relations requires judicious grouping, or lumping as it is called, to minimise considering defects as one whose diversities would obscure aetiology. The dangers here are analytical impracticability on the one hand, and loss of biological sense, as it has been called, on the other. However necessary, careful attempts at logical grouping have not been sufficient to render more than a minimal conclusion. ${ }^{14}$

\section{CLASSIFICATION BY PATHOGENESIS}

Congenital malformations have also been classified according to the abnormal developmental pathways by which they come into being, sometimes called by the term 'mechanism'. The latter has come to have several connotations, discussion of which would take this article far afield. What are considered here are merely suggested schemes using descriptive categories of processes or entities. One such plan, of general nature, was mentioned years ago $^{15}$ when it was proposed that "distinctive terms for those congenital malformations which originate in the organogenetic period ...and for those caused in the period of fetal growth...would be useful". Yet later the same author ${ }^{16}$ expressed doubt that the one sort of malformation could always be distinguished from the other.

Another suggested division ${ }^{17}$ consisted of general types of abnormal embryological processes, developmental arrest, abnormal resorptive events, secondary destruction, etc. In this vein a list was offered ${ }^{8}$ of more specific anomalous actions, such as failure to form or form properly, retrogress, close, open, remain open, unite, etc. A later variation on this design differentiated between processes leading to intrinsic and extrinsic congenital abnormalities, between organ and tissue defects, etc. ${ }^{18}$ It and others of similar intention ${ }^{19} 20$ were as much devoted to questions of nomenclature as of classification and will be discussed below.

\section{Nomenclature}

What we call a thing often determines how we think about it, despite a well known author's "what's in a name?" Thus the name "teratology', by which the science of congenital malformations is called, by its history informs us of the breadth and depth of the phenomena the science has set itself to comprehend. To begin with, it is a misconception that the Greek root teras (= marvel, monster), from which the word is derived, refers to monstrosity in its 
present day sense of grotesquely unnatural. Its true sense is shown by the etymology of 'monster', namely, to show or forecast. But teratology has taken on wider meanings than its original one, just as, for example, the word democracy has evolved from its ancient significance of a form of government in which the entire citizenry comprised the legislative body.

Surprisingly, the word teratology made its debut not too long ago, in 1678, as the title of a work devoted to a discourse on prodigies and wonders, according to that vast repository of miscellanea, the Oxford English Dictionary. ${ }^{21}$ But while from the start the word referred to things out of the ordinary, not until a century and a half later did it come to refer to the study of anomalies of organisation, as the title of Isadore Geoffroy Saint-Hilaire's great work indicates. ${ }^{22}$ Thus, today teratology, for example as defined by Dorland's Medical Dictionary, is the science that deals with abnormal development and congenital malformations, without reference to monstrosities, and is the one accepted by the medical world.

Nevertheless, attempts have been made to revise the course of lexical history by attributing to teratology a meaning it never had: the "study of monsters". ${ }^{23}{ }^{24}$ And because teratology was erroneously believed to have this constricted meaning, and supposedly suggested "to the clinician an environmental cause...", the neologism 'dysmorphology' was introduced for the purpose of rectifying these supposed inadequacies. Dysmorphology was then defined as "the study of...abnormal development of tissue form", which supposedly avoided the "indication of the degree of malformation, its timing, or its mode of origin".

But this new word, limited by this narrow sense, cannot hope to replace one with a richness of connotation such as teratology has. An instance of the latter is attested by a classic formulation of the subject matter of teratology. "Congenital malformations are structural defects present at birth. They may be gross or microscopic, on the surface of the body or within it, familial or sporadic, hereditary or nonhereditary, single or multiple". ${ }^{15}$ Thus, because it provides nothing new and can cause only confusion, though it is probably already too late to do so, the neologism should be limited in use or even abandoned.

It must be added that the assertion that the word teratology is presently "becoming restricted in use almost exclusively to the experimental production of congenital malformation" 24 is equally mistaken, though it must be admitted that animal teratologists have themselves sometimes fed this notion. ${ }^{25}$ On the contrary, the word conveys the breadth of its applicability by the existence of its various subdivisions, such as clinical teratology, epidemiological teratology, experimental teratology, toxicological teratology.

Another effort to displace a venerable term concerns 'congenital malformation' itself. It seems to have begun in 1963, when in a multiauthored book ${ }^{26}$ 'birth defects' apparently was first used as a synonym for congenital malfor- mations. It was introduced under the auspices of The National Foundation, which after leading in the successful campaign to conquer poliomyelitis in the 1950 s turned its energies to the struggle of dealing with the even more formidable problem of congenital malformations. No doubt the motivation for coining the new term was to make these abnormalities more meaningful to the general public and gain its support in the Foundation's new campaign.

However praiseworthy this purpose may have been thought to be, the reason behind it would seem to be condescending, in not believing that ordinary people could understand and respond to conventional medical terminology. But a primary objection to the term is that it can lead to the idea that malformations result 'from' birth rather than being present 'at' birth, and thus tends to distort a fundamental tenet of teratology and mislead as to the origin and causation of such abnormalities. Unfortunately, the term has caught on and its use is widening, abetted as it has been by some medical people and others.

\section{Taxonomic innovations}

Other motives guided an international group of scientists to devise a new taxonomic scheme for the nomenclature of congenital malformations. This new scheme, it was held, would improve diagnosis, management, and counselling, as well as aid in malformation identification by health professionals and "workers in the field of fundamental research on morphogenesis". ${ }^{19} 20$

For these purposes the group suggested that human congenital abnormalities be divided and defined as follows: malformation, a primary structural defect, distinguished from deformation, an alteration in a previously normally formed part; anomalad, a malformation together with its subsequently derived structural changes; syndrome, a recognised pattern of malformations with a given aetiology; and association, a pattern of malformations, not a syndrome or anomalad. In addition, an elaborate system of naming multiple malformations and syndromes was sketched in and discussed extensively.

Further attempts to refine the teratological vocabulary were especially aimed at enabling the retrospective charting of maldevelopmental pathways and interrelationships. ${ }^{182427}$ Various patterns of abnormal morphological development were discussed, with emphasis on how knowledge of them could make for understanding of the causal and pathogenetic relationships of anatomically distinct constituents of multiple malformations, and thus enable distinguishing, for example, syndromes and sequences (the latter replacing the by then superseded anomalad).

The question of how single aetiological factors produce combinations of malformations, whatever the latter are called, syndrome, anomalad, association, sequence, has long been debated. It had been explored years before by Grüneberg ${ }^{28}$ in discussing a type of pleiotropism, in his case the manifold morphological effects of individual genes. He concluded, and it is widely agreed, that teratogenic factors 
cause multiple abnormalities either, to use his terminology, by coordinated actions on different parts of the body, or by subordinated ones, that is, "a cascade of secondary and tertiary gene effects with a hierarchy of causes...". It is probable that all human and animal teratogens, whether genetic, chromosomal, or environmental, are confined to the same courses of action. Grüneberg's hypotheses were based not on theoretical speculations, but on experimental evidence obtained by studying rodent abnormal prenatal maldevelopment. Abnormal morphogenetic pathways, he would have maintained, are not revealed by examining malformed newborns.

This viewpoint was later accepted, with a qualification, when it was written, "It is not possible to reconstruct the events that lead to malformations when one merely examines the end product [but] meaningful speculation is possible...". ${ }^{27}$ Also, "although the exact cause and pathogenesis of a given anomaly may not be known, careful analysis of the history and physical findings of the patient and judicious inference from experimental data frequently give useful ideas about its probable cause and pathogenesis". ${ }^{18}$

Through such judgment, it was also believed, the practicalities of managing and preventing anomalies would be forthcoming. But this is to be achieved, and this is the point that was being made, only by the use of "proper terms" for concepts and terminology of errors of morphogenesis. ${ }^{18}$ These terms consist of innovative designations and novel definitions, which transform descriptive terminology into aetiological ones. Hence, according to this scheme, the new expressions no longer pertain only to entities, but primarily refer to their origin: 'malformation' would signify a defect of a part destined to abnormality, endowed thus from the moment of fertilisation, and 'disruption' a defect not inherent but of secondary, that is, environmental, origin.

Confusion not clarification was soon the outcome. Regarding 'anomalad', the deviser of the term, who had offered it in a playful moment, ${ }^{30} 31$ noted a serious concern: the epithet was being applied loosely, "that is, groups of anomalies are being called anomalads when there is no convincing evidence that they do stem from a common primary developmental error...". A discussion of the clinical importance of delineating malformation syndromes in accordance with some new terms was most unhelpful. ${ }^{32}$ Others admitted that "postnatally, it may be impossible to determine if a given anomaly is a malformation or a disruption". ${ }^{18}$ A respected investigator has said that "because of the difficulties in doing the types of genetically manipulative experiments that are possible in the mouse and lower organisms, the clear separation of apparently related disorders into aetiologically distinct entities is not always possible and sometimes degenerates into semantic disputations that severely strain one's logical faculties". ${ }^{33}$ How these and the other newly introduced terms could have "relevance to diagnosis, management and counselling" is not easy to see.

\section{The developmental field concept}

The linchpin in this argument is the developmental field concept, a hypothesis borrowed from normal ontogenesis, which was described as "one of the most astounding developments in Western scientific history...". ${ }^{34}$ The developmental field is a "part of the embryo in which the processes of development of the complex structure appropriate to that part are controlled and coordinated" and, with reference to abnormal development, is defined or identified when "an anatomically identical complex malformation...is seen in two or more causally different conditions" [italics in original]. ${ }^{24}$

Rephrased, this means that when different disturbing agents cause similar abnormalities it is because they are acting on the same developmental field, and conversely if a given abnormality is caused by two different agents this is evidence of an underlying developmental field. It has been suggested ( F C Fraser, personal communication), however, "that the last step in this chain of reasoning is fallacious as in the syllogism 'all As are Bs, therefore all Bs are As'. Nevertheless, a long series of malformations have been designated field defects on the grounds that they are causally heterogeneous. Even if it were not fallacious, this confusion is not very useful since it is difficult to imagine a malformation that is not causally heterogeneous".

It may be too soon, only a decade or more after the hope expressed of the new scheme of nomenclature, that classifying multiple malformation patterns based on the hypothetical morphogenetic relations of their constituent parts would permit "analysis of birth defects" and would lead to the prevention of congenital malformations, to have expected such accomplishments. The future may bring success, but it is not unreasonable to believe that theoretical considerations alone will not supply the answers.

Meanwhile, from where might answers be forthcoming? Will they come from studies of the molecular biology of prenatal development of the sorts recently reported, ${ }^{35}{ }^{36}$ studies from which are proceeding extraordinary findings? No doubt such investigations are enlarging enormously the boundaries of understanding of the bases of abnormal embryological processes and of differential reactions to adverse environmental circumstances, and it is to be hoped in time they will point to ways of prevention, since that is one, if not the sole, purpose of it all, it no longer being fashionable, as it once was in some scientific fields of endeavour, to deride goal mindedness. Whatever is the reason for the change of attitude, let it be praised.

1 Onions CT, ed. The shorter Oxford English dictionary on historical principles. London: Oxford University Press, 1965. Morris W, ed. The American heritage dictionary of the English language. New York: American Heritage, 1969.

3 Anon. Manual of the international statistical classification of Anon. Manual of the international statistical classification of diseases, injuries, and causes

4 Neel JV. A study of major congenital defects in Japanese infants. Am f Hum Genet 1958;10:298-445.

5 Kalter H, Warkany W. Congenital malformations: etiologic factors and their role in prevention. $N$ Engl $\mathcal{F}$ Med 1983;308:424-31, 491-7. 
6 Gruenwald P. Mechanisms of abnormal development. I. Causes of abnormal development in the embryo. Arch Pathol 1947;44:398-436.

7 Penrose L. Heredity and environment in the causation of foetal malformation. Practitioner 1951;166:429-35.

8 Potter EL. Classification and pathology of congenital anomalies. Am f Obstet Gynecol 1964;90:985-93.

9 Davison C. Definition and classification of human malforDavison C. Definition and classification of hum

10 WHO Staff. ICD-10: international statistical classification of diseases and related health problems. Vol 1. Tabular list. 10th ed. Geneva: World Health Organization, 1992

11 Taffel S. Congenital anomalies and birth injuries among live births: United States, 1973-74. DHEW Publication No 79-1909. Hyattsville, MD: National Center for Health Statistics, 1978.

12 Edwards JH, Leck I, Record RG. A classification of malformations. Acta Genet 1964;14:76-90.

13 Leck I, Record RG, McKeown T, Edwards JH. The incidence of malformations in Birmingham, England, 1950-1959. Teratology 1968;1:263-80.

14 Robert E, Harris J, Källén B. The epidemiology of limb malformations. Reprod Teratol 1997;11:653-62.

15 Warkany J. Etiology of congenital malformations. Adv Pedi-

atr 1947;2:1-63.
16 Warkany J. Congenital malformations: notes and comments. Chicago: Year Book Medical Publishers, 1971:5.

17 Patten BM. Varying developmental patterns in teratology. Pediatrics 1957;19:734-48

18 Spranger J, Benirschke K, Hall JG, et al. Errors of morphogenesis: concepts and terms: recommendations of an international working group. $\mathcal{F}$ Pediatr 1982;100:160-5.

19 Christiansen RL. Classification and nomenclature of morphological defects. Lancet 1975;i:513.

20 Smith DW. Classification, nomenclature, and naming of morphologic defects. $\mathcal{F}$ Pediatr 1975;87:162-4.

21 Anon. The compact edition of the Oxford English Dictionary. Oxford: Oxford University Press, 1971.

22 Saint-Hilaire IG. Histoire générale et particulière des anomalies de l'organisation chez l'homme et les animaux: ouvrage comprenant des recherches sur les caractères, la classification, l'influence physiologique et pathologique, les rapports généraux, les lois et les causes des monstruosites, des varietes et vices de conformation, ou traité de tératolgie. Paris: Baillière, 1832-37.

23 Smith DW. Dysmorphology (teratology). $\mathcal{F}$ Pediatr 1966;69: $1150-75$.

24 Opitz JM, Gilbert EF. Pathogenetic analysis of congenital anomalies in humans. Pathobiol Ann 1982;12:301-49.

25 Wilson JG, Fraser FC. Preface. In: Wilson JG, Fraser FC, eds. Handbook of teratology. Vol 1. General principles and etiology. New York: Plenum Press, 1977:vii-viii.

26 Fishbein M, ed. Birth defects. Philadelphia: Lippincott, 1963.

27 Opitz JM, Herrmann J, Pettersen JC, Bersu ET, Colacino SC. Terminological, diagnostic, nosological, and anatomical-developmental aspects of developmental deanatomical-developmental aspects of develo
fects in man. Adv Hum Genet 1979;9:71-164.

28 Grüneberg $\mathrm{H}$. An analysis of the 'pleiotropic' effects of a new lethal mutation in the rat (Mus norvegicus). Proc $R$ Soc Lond B 1938;125:123-44.

29 Grüneberg H. The pathology of development. A study of inherited skeletal disorders in animals. New York: Wiley, 1963

30 Fraser FC. Anomaly vs polyanomaly. F Pediatr 1976;88:900.

31 Fraser FC Of mice and children: reminiscences of a teratogeneticist. In: Kalter $\mathrm{H}$, ed: Issues and reviews in terateratogeneticist. In: Kalter $\mathrm{H}$, ed: Issues and reviews in
tology. Vol 5. New York: Plenum Press, 1990:1-75.

32 Polani P. Delineation of malformation syndromes. In: Littlefield JW, de Grouchy J, eds. Birth defects: proceedings of the fift international conference. Amsterdam: Excerpta Medica, 1978:422-25.

33 Epstein CJ. Developmental mechanisms and abnormalities: toward a developmental genetics of man. In: Littlefield JW, de Grouchy J, eds. Birth defects: proceedings of the fifth international conference. Amsterdam: Excerpta Medica, 1978: 387ional

34 Opitz JM. The developmental field concept. Am $\mathcal{f} \mathrm{Med}$ Genet 1985;21:1-11.

35 Tickle C. Genetics and limb development. Dev Genet 1996; 19:1-8.

36 Wehr R, Gruss P. Pax and vertebrate development. Int $\mathcal{f}$ Dev Biol 1996:40:369-77. 